\title{
Sexual and Marital Satisfaction among Vietnamese People
}

\author{
Trinh Thi Linh
}

Faculty of Psychology, University of Social Sciences and Humanities (VNU-Hanoi), 336, Nguyen Trai, Thanh Xuan, Hanoi, Vietnam

Email:anhlinh huong@yahoo.com Tel:+84.243.5585419

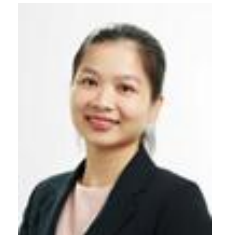

Theck for updates

\begin{abstract}
Given the context of sexual satisfaction studies in general as well as the correlation between sexual satisfaction and marital satisfaction studies in particular are rather short in number in Vietnam, this study is to further research into the said topics upon 289 Vietnamese intellectuals respondents living and working in Hanoi. Utilizing marital satisfaction measurement sub-scale from the Dyadic Adjustment Scale of Spanier and self-designed sexual satisfaction based on Marital Satisfaction Inventory of Snyder, the results of this study recognized the moderate level of sexual and marital satisfaction of respondents. Independent Sample T-test did not show the significantly statistically difference between male and female upon these two dimensions. Linear regression analysis, using sexual satisfaction as the dependent variable recognizes a significant portion of the variation in marital satisfaction. However, it's the same portion of the variation when using marital satisfaction as the dependent variable. Linear multiple regression also recorded the influence of the expectation on sex life of the intellectuals regarding their sexual satisfaction. Nonetheless, regarding the interrelation of the marital satisfaction, the dominance of the level of expectation to sexual satisfaction is insignificant. Some limitations of this study are also well pointed out from actual collected results.
\end{abstract}

Keywords: Sexual satisfaction, Marital satisfaction, Vietnamese people, Dyadic adjustment scale, Intellectual, Correlation.

\section{Introduction}

It is can discussed about researches on marriage all over the world that there is an interrelation between sexual satisfaction and couple relationship quality. Having been approached by bottom-up processing method, a number of studies has recognized the sexual satisfaction as a vital aspect in marriage. To state it other way, individual's sexual satisfaction is considered as one of the most important factors affected the contentment in her/his life in general and the contentment in her/his marriage in particular (Farley and Davis, 1980; Hurlbert et al., 1993; Barrientos and Páez, 2006; Yeh et al., 2006; Rosen and Bachmann, 2008; Davison et al., 2009; Long et al., 2011). Specifically, results of some studies also indicated that sex is considered an important dimension to measure the quality of marriage life (Christopher and Sprecher, 2000; Sprecher, 2002; Dzara, 2010). However, it can be seen from topdown processing approach that the couple relationship quality has significantly directed the couple's perspective on their sexual satisfaction in marriage. For instance, when one finds it satisfied talking about their relationship, they might base on their positive assessment on relationship to assess the detailed aspects of their relationship. It is often observed that the aspects assessed by the said people are more affirmative. In contrast, when one is dissatisfied with their relationship, they are likely to place on their negativity of the general relationship to determine the particular faces of the liaison; and given this case, the weighed particular faces are more negative. With Interpersonal Exchange Model of Sexual Satisfaction, Lawrance and Byers (1995) recognized that those with unresolved conflicts, unfelt sentiments and distant in relationship are recorded with low sexual satisfaction. MacNeil and Byers (2005) also recognized that relationship satisfaction mediated partial of the association between self-disclosure and sexual satisfaction. The top-down processing method was also pointed in the study of Brezsnyak and Whisman (2004). Nonetheless, it is vital to realize that up to the present, the evidences of marital satisfaction foreseen sexual satisfaction are not consistent, especially in longitudinal researches. In research of Yeh et al. (2006) it was confirmed the forecast of sexual satisfaction factor to marriage life, yet they could not indicate the forecast of marital satisfaction in general to sexual satisfaction. Similarly, in Sprecher's study (Sprecher, 2002) he encountered difficulties in confirming the meaningful relation between those two said factors.

Beside the bottom-up and top-down processing approaches, it was noted from the literature review that the correlation between marital satisfaction and sexual satisfaction was bidirectional (Henderson-King and Veroff, 1994; Byers, 2005; Wenner, 2010). This was to assert that marriage sexual satisfaction bore influence on marital satisfaction in general and on the contrary, marital satisfaction contained forecast possibility on sexual satisfaction changes. In Vietnam, sex life is considered as “a bad joke”. As a result, in a long time, sexual activities in general and sexual in marriage in particular are considered as tough issue, and neglected in studies. Till the last XIX century and the beginning of XX century, sexual related issues in marriage had began to come into concern under 
sexual violence (Khuat et al., 2009). Recently, the topic of sexuality in general as well as sexual satisfaction has been mentioned more openly by Vietnamese researchers but it still seems to be quite modest in terms of quantity. Some authors consider sexual satisfaction as an aspect of general marriage/family satisfaction (Nguyen, 2016; Do and Bahr, 2017) some others regard from the bottom-up processing approach to consider sexual satisfaction as a factor affecting Vietnamese marital satisfaction (Bui, 2008; Nguyen, 2015; Le et al., 2017; Luu, 2017). Up to now, the literature review on this topic in Vietnam has not allowed to acknowledge any publication discussing the relationship between sexual satisfaction and marital satisfaction under the top-down processing perspective. Therefore, the main purposes of the current study were not only to provide some data on sexual satisfaction but to investigate the relationship between sexual and marital satisfaction in a sample of married Vietnamese people as well.

\section{Methods}

\subsection{Participants and Procedure}

Participants for the study were obtained from a convenience sample of 164 couples living in Hanoi, Vietnam. It is required that respondents be at least 18 years old and currently in an intact couple relationships. Among 164 couples, there were 39 couples, in which either of the partners (husband or wife) returned the questionnaire only. Thus, the total subjects were 145 women and 144 men $(\mathrm{N}=289)$. The mean age of the sample was 31.6 years old $(\mathrm{SD}=5.40)$. The demographic characteristics of participants were explicated in Table 1:

Table-1. Demographic characteristics of participants.

\begin{tabular}{c|c|c}
\hline Characteristics & Values & Percent \\
\hline Gender & Male & 49.83 \\
\hline & Female & 50.17 \\
\hline Education & College & 23.53 \\
\hline & University & 54.67 \\
\hline Age & Post graduated & 21.80 \\
\hline & $22-30$ & 44.30 \\
\hline & $31-40$ & 49.80 \\
\hline & $41-60$ & 5.90 \\
\hline
\end{tabular}

The questionnaire was sent to the spouses selected in separate envelop with an invitation letter. This one explained the purpose of the study and encouraged the spouses to join in the survey to help improve the empirical research in this field in Vietnam. Additionally, spouses were instructed to complete the questionnaires independently. It took 25-30 minutes to complete the survey.

Information obtained is guaranteed of confidently as well as the personal information of respondents is kept anonymous.

\subsection{Survey Instrument and Measures Used}

Background Questionnaire: A background questionnaire was used to collect demographic information such as gender, age, educational background.

\section{Sexual Satisfaction Measurement Tool Set}

As mentioned, though sexual related topics are seen more openly in society nowadays in comparison to the past, it does not go together with the easy findings to learn about them, especially for group of high education people. That is to imply the necessity when reviewing, discussing about sexual topic, socio-cultural factor should be greatly concerned. Therefore, despite the number of sexual satisfaction scales in the world (eg, Global Measure of Sexual Satisfaction, Lawrance and Byers (1998) Sexual Satisfaction Scale of the Derogatis Sexual Functioning Inventory, Derogatis and Melisaratos (1979) in the scope of this research, we would like to apply the approaches that we find them suitable with Vietnamese culture. To explain, in addition to go into details about feeling of subjects, sexual satisfaction measurement toolsets in the world usually focuses on both sexual behavior and sexual frequency, which are not easily obtained through reliable mass surveys for Vietnamese people. Consequently, in this exploring research, so as to avoid the shyness of the subjects in the process of filling in the questionnaire, we had chosen to design items that focus primarily on reflecting their feelings towards their sex life.

Therefore, 8 items on a 6-point Likert scale concerning feelings that respondents expressed about their sexual relationship were used to assess sexual satisfaction (e.g., "You are willing to have sex with your spouse," "You and your spouse are turned on when having sex"). Among these 8 items, 5 items were built from Snyder's MSI scale (Snyder, 1983) and 3 items were designed based on the comments we obtained from the exploration survey. Based on the corrected item-total correlation, 01 item has been removed due to this lower correlation ("You want to further improve the quality of sexual relations between you and your spouse"). The remaining 7 items has met the mathematical statistical parameters $(\alpha=0.73$, the corrected item-total correlation run from 0.34 to 0.50$)$. Responses to these 7 items were reversed when appropriate and calculated to form a score of sexual satisfaction with higher scores indicating higher levels of sexual satisfaction.

\section{Marital Satisfaction Measurement Toolset}

A marital satisfaction sub-scale consisting of 10 items in Spanier's Dyadic Adjustment Scale (Spanier, 1976) was applied in this study. Responses to these 10 items were reversed when appropriate and calculated to form a score of marital satisfaction, with higher scores indicating higher levels of marital satisfaction. Internal consistency of this measure was favorable in the current sample $(\alpha=0.75$, the total correlation coefficient ranges from 0.34 to $0.50)$. 


\subsection{Data Analysis}

Statistical calculations were performed using SPSS (Statistical Package for the Social Sciences) version 22.0. In this research, SPSS supported all the statistical methods, including descriptive statistics, bivariate correlations, independent samples $\mathrm{T}$ test, linear and multiple linear regressions. The correlations allowed us to identify the existence of relationships between marital and sexual satisfaction. The independent samples $\mathrm{T}$ test performed a statistically significant difference between men and women participating in the study regarding two aspects of marital and sexual satisfaction. The linear and multiple linear regressions were enabling us to predict the value of marital satisfaction on sexual satisfaction or vice versus.

All of the negative items were recoded before conducting data processing operations. All scales are tested for Cronbach Alpha reliability, ensuring to meet the mathematical statistical requirements before performing further analysis for research purposes.

\section{Results}

3.1. Mean Scores for Sexual Satisfaction and Marital Satisfaction

Data involving descriptive statistics for sexual satisfaction and marital satisfaction are presented in Table 2.

Table-2. Descriptive Statistics and Gender Differences for Sexual and Marital Satisfaction.

\begin{tabular}{|c|c|c|c|}
\hline \multirow{2}{*}{ Variables } & \multicolumn{3}{|c|}{ Mean (SD) } \\
\hline & Male & Female & Total \\
\hline Sexual satisfaction & $3.80(0.63)$ & $3.76(0.65)$ & $3.78(0.64)$ \\
\hline You feel uncomfortable when having sex with your spouse* & $3.82(1.01)$ & $3.81(1.00)$ & $3.81(1.01)$ \\
\hline You have sex with your spouse for the responsibility* & $3.93(1.07)$ & $3.99(1.05)$ & $3.96(1.07)$ \\
\hline You and your spouse rarely have sex* & $3.99(1.21)$ & $3.94(1.26)$ & $3.97(1.23)$ \\
\hline You and your spouse are turned on when having sex & $3.71(1.04)$ & $3.62(0.99)$ & $3.66(1.02)$ \\
\hline Marital satisfaction & $3.62(0.54)$ & $3.59(0.56)$ & $3.61(0.55)$ \\
\hline $\begin{array}{l}\text { How often do you discuss or have you considered divorce, separation, or } \\
\text { terminating your relationship?* }\end{array}$ & $4.13(0.98)$ & $4.04(1.04)$ & $4.08(1.01)$ \\
\hline How often do you or your mate leave the house after a fight?* & $3.94(1.07)$ & $3.96(1.00)$ & $3.95(1.03)$ \\
\hline How often do you and your partner quarrel?* & $3.43(0.83)$ & $3.37(0.86)$ & $3.41(0.85)$ \\
\hline How often do you and your mate "get on each other's nerves"?* & $3.57(0.94)$ & $3.61(0.88)$ & $3.59(0.91)$ \\
\hline Do you kiss your mate? & $2.50(0.92)$ & $2.62(0.88)$ & $2.56(0.90)$ \\
\hline The degree of happiness considered in all aspects of your spousal relationship & $3.14(0.91)$ & $3.08(1.02)$ & $3.11(0.97)$ \\
\hline How do you feel about the future of your relationship? & $4.02(0.94)$ & $3.99(1.00)$ & $4.01(0.97)$ \\
\hline
\end{tabular}

* Negative items have been recoded. The higher the average score corresponds, the higher the level of sexual satisfaction and the higher the satisfaction of marriage is.

Overall, both husbands and wives reported quite moderate in sexual and marital satisfaction, in which the interviewed husband planned to assess a little more positively about the sex life as well as the marriage life in comparison with the wife, the average score is 3.80 and 3.76 for sexual satisfaction, respectively; 3.62 and 3.59 for marital satisfaction, respectively. In particular, the interviewed husbands claimed that they were more excited than the wives when having sex with the average score of 3.71 and 3.62. The husbands also affirmed that they were more voluntary than their wives in their sexual relations with the average score of 3.93 compared with that of 3.81 from the wives. This is similar to their recognition of the level of satisfaction in marriage life. The husbands were questioned rating their happiness in married life higher than that of his wife with 3.14 (SD = 0.91) compared to $3.08(\mathrm{SD}=1.02)$. They also felt a bit more positive than their wives about their relationship in the future with the average score respectively of 4.02 and 3.99. In other words, it seems that the husbands in the current study tended to be more contented than the wife in the sex life as well as in the married life. However, Independent Sample Ttest results on the total samples demonstrated that this difference was not statistically significant $\left(\mathrm{t}_{\text {maritalsatisfaction (285) }}\right.$ $\left.=.496, \mathrm{p}>.05 ; \mathrm{t}_{\text {sexualsatisfaction }(284)}=.63, \mathrm{p}>.05\right)$.

\subsection{Results from Correlations}

The bivariate correlation (Pearson) analysis allow us to consider that sexual and marital satisfaction were positively associated $(\mathrm{r}=.56)$. In another term, results indicated that greater sexual satisfaction was associated with greater marital satisfaction.

\subsection{Results from Multiple Regression Analysis}

With the assumption of sexual satisfaction as an independent variable, the results of linear regression expressed that this independent variable explained $30.9 \%$ of the variation in marital satisfaction scores. On the contrary, with the assumption of marital satisfaction as an independent variable, we also interpreted an absolutely similar result in explaining the variation of sexual satisfaction score. Specifically: marital satisfaction is capable of forecasting $30.9 \%$ of the variation in sexual satisfaction. Thus, it can be seen that the relationship between sexual satisfaction and marital satisfaction is recognized as bidirectional in this group. 
Table-3. Linear and Multiple Linear Regression analysis predicting sexual satisfaction

\begin{tabular}{|c|c|c|c|c|c|c|c|c|c|c|}
\hline \multirow[b]{5}{*}{$\beta$} & \multicolumn{5}{|c|}{ Model 1} & \multicolumn{5}{|c|}{ Model 2} \\
\hline & \multicolumn{5}{|c|}{ Marital satisfaction } & \multicolumn{5}{|c|}{$\begin{array}{c}\text { Marital satisfaction }^{\mathrm{a}} \\
\text { The responsiveness of sex life in comparison to } \\
\text { expectations }^{\mathrm{b}}\end{array}$} \\
\hline & $\mathbf{R}$ & $\begin{array}{l}\text { Adjusted } \\
\text { R Square }\end{array}$ & $\begin{array}{l}\text { R Square } \\
\text { change }\end{array}$ & Fchange & Sig.F & $\mathbf{R}$ & $\begin{array}{l}\text { Adjusted } \\
\text { R Square } \\
\end{array}$ & $\begin{array}{l}\text { R Square } \\
\text { change }\end{array}$ & Fchange & Sig.F \\
\hline & .558 & .309 & .311 & $\begin{array}{l}\mathrm{F}(1,283) \\
=127.838\end{array}$ & .000 & .579 & .330 & .024 & $\begin{array}{c}\mathrm{F}(1,282) \\
=10.009\end{array}$ & .002 \\
\hline & & & & .558 & & & $.498(\mathrm{a})$ & & .165 & \\
\hline
\end{tabular}

In addition to understanding the predictability of marital satisfaction to the sexual satisfaction level of participants in the survey, the results also indicate that sexual satisfaction is still affected by couples' expectations about sex life. Specifically, when considering the impact variable is marital satisfaction and the sexual satisfaction adaptation level in comparison to expectations, the ability to foresee changes in sexual satisfaction scores has increased from $30.9 \%$ to $33 \%$. Nevertheless, the data in Table 3 also allow to affirm that in comparison with marital satisfaction, the effect of the level of expectation of sex life to the level of sexual satisfaction is quite modesty $(\beta=$ $.165)$.

The question is whether the sexual satisfaction impact on marital satisfaction in general is disparate by gender criteria? The single linear regression results recorded a higher percentage of data interpreting the variability of data in men in this respect. Specifically: While sexual satisfaction explained $32.4 \%$ of the variation in marital satisfaction scores in men, the respondents said that this ratio was $29 \%$ only refer to Table 4.

Table-4. Linear Regression analysis predicting Marital Satisfaction by gender

\begin{tabular}{c|r|r|r|r|r|r|r|r|r}
\hline \multicolumn{2}{r}{} & $\mathbf{R}$ & \multicolumn{2}{c}{ Adjusted R Square } & \multicolumn{2}{c}{ R Square change } & \multicolumn{2}{c}{ Fchange } & \multicolumn{2}{c}{ Sig.F } \\
\hline Male & Female & Male & Female & Male & Female & Male & Female & Male & Female \\
\hline .573 & .543 & .324 & .290 & .328 & .295 & 68.441 & 58.914 & .000 & .000 \\
\hline
\end{tabular}

* Predictor: Sexual Satisfaction.

\section{Discussions}

\subsection{Sexual and Marital Satisfaction by Gender}

The current study provided descriptive data regarding sexual and marital satisfaction of married Vietnamese people. Generally seen from the results, in general, participants were asked to be moderately satisfied with their sexual and marital satisfaction. This satisfaction level demonstrates no statistically significant difference between men and women. Although some researches on the Asian groups have shown that in Eastern countries, it seems that sexual pleasure is more important in men than in women (Pan, 1993; Evans, 1995) what is shown in this study is considered to be in agreement with some previous studies (Lawrance and Byers, 1995; Dzara, 2010). However, we are aware of the fact that not recognizing the difference between married men and women in terms of overall marital satisfaction, especially the level of sexual satisfaction, can come from the measurement tool itself, which was designed by us. Accordingly, the set of sexual satisfaction measurement tools mainly focuses on the respondents' feelings; meanwhile, the tools almost ignore the attitude and behavior which can make more significant difference between men and women considering this topic.

Regarding the predictability of marital satisfaction to the variability of sexual satisfaction (as well as the opposite direction), the data obtained allow the recognition of similarities with what Przybyla and Byrne pointed out (Przybyla and Byrne, 1981). Accordingly, these authors found that for men, sexual satisfaction is an important factor in determining their overall satisfaction with married life. Meanwhile, for women, marital satisfaction in general is an important factor in determining the quality of their sexual relationship. In other words, while men tend to recognize the relationship between these aspects in the bottom-up processing approach, women tend to see it in the top-down processing. It is reasonable to say that explanations from a socio-cultural and biological perspective can partly explain this difference. According to socio-culturally reasons, Baumeister (2000) argued that women exhibited a higher erotic plasticity than men. And because women, but not men, in traditional Vietnamese society have been socialized not to expect pleasure from sex, it is possible that the marital/family relationship is all for them. Perhaps, therefore, the expectation of sex life only dominates a very small part of the variation in marital satisfaction on this respondent group. Biologically, Diamond (2003) pointed out that neural mechanisms of the sexual and attachment systems overlap more strongly among man than women.

\subsection{Correlation between Sexual and Marital Satisfaction}

The study pointed out that participants with greater sexual satisfaction was associated with greater marital satisfaction. This finding supports results from the research of Schenk and his colleagues (Schenk et al., 1983) who found that husbands' and wives' ratings of satisfaction with their sexual interactions were significantly related to the overall quality of their marital satisfaction. It is also consistent with previous research in recent years (Purnine and Carey, 1997; Renaud et al., 1997; Byers, 2005).

Interestingly, the current study was the first in Vietnam to provide evidence for the bidirectional association between sexual satisfaction and marital satisfaction. Specifically, sexual satisfaction predicts marital satisfaction (especially for men), and marital satisfaction predict also sexual satisfaction (especially for women). In addition to the explanations coming from the socio-cultural and biological perspective, it is also possible to explain this from the expectancy-value theory of Fishbein and Azjen (1975) as well as the theory of social cognition of Fiske and Taylor (2008). According to expectancy-value theory, a person's assessment of their sexual relationship can predict their assessment of the overall relationship in general. Since the theory of value expectations poses that a person's assessment of a certain aspect/field often operates in accordance to their beliefs in that aspect/field. Consequently, when they have positive beliefs about a certain aspect/field of the relationship, such as the sexual aspect, it is very 
easy that they will be able to obtain a positive overall assessment of the relationship. Additionally, theories and studies in the field of social awareness also suggest that general belief can form a person's perception of a particular field. In other words, when one has a positive outlook on their relationships, they can easily tend to be positive about the specific areas occurring in those relationships.

\section{Conclusion}

The current study examined sexual satisfaction, marital satisfaction and the relationship between them in Vietnamese sample. As one of the first researches in this area in Vietnam, the results add up to our standing of the association between these two variables. From this research, we would expect that it will open new directions for researchers in this field, particular in understanding the relationship between marital and sexual satisfaction.

\section{Limitation of Current Study}

Though the collected data has met the scientifically requirement, the generalization of the results from this study may be limited for some reasons.

Firstly, the respondents were consisted only the highly educated individuals. Even though Rainer and Smith (2012) has illustrated that the educational level does not directly influence the sexual satisfaction, it is still a secondary factor in the relationship between communication and sexual satisfaction. I assume that the education level dominates the way people see and evaluate issues in life.

Secondly, this study was based on convenience sampling, focusing on couples currently living and working in Hanoi. Therefore, the representativeness of the Vietnamese subject is not fulfilled.

Thirdly, research is carried out under cross-sectional study. In as much as, the results obtained of the two-way relationship between sexual satisfaction and marital satisfaction should be viewed in moderation. To be more specifically, it is necessary to have longitudinal studies to be carried out in this area, and then the argument for this relationship will certainly be more convincing.

\section{References}

Barrientos, J.E. and D. Páez, 2006. Psychosocial variables of sexual satisfaction in Chile. Journal of Sex \& Marital Therapy, 32(5): 351368.Available at: https://doi.org/10.1080/00926230600834695.

Baumeister, R., 2000. Gender differences in erotic plasticity: The female sex drive as socially flexible and responsive. Psychological Bulletin, 126(3): 347-374.Available at: https://doi.org/10.1037//0033-2909.126.3.347.

Brezsnyak, M. and M.A. Whisman, 2004. Sexual desire and relationship functioning: The effects of marital satisfaction and power. Journal of Sex \& Marital Therapy, 30(3): 199-2 17.Available at: https://doi.org/10.1080/00926230490262393.

Bui, V., 2008. Husband and wife sexual intercourse and its relationship with the satisfaction of marriage in the family in rural areas today (Through surveys in Phu Linh commune, Soc Son district, Hanoi). Journal of Psychology, 1(106): $52-56$.

Byers, E.S., 2005. Relationship satisfaction and sexual satisfaction: A longitudinal study of individuals in long-term relationships. Journal of Sex Research, 42(2): 113-118.Available at: https://doi.org/10.1080/00224490509552264.

Christopher, F.S. and S. Sprecher, 2000. Sexuality in marriage, dating, and other relationships: A decade review. Journal of Marriage and Family, 62(4): 999-1017.Available at: https://doi.org/10.1111/j.1741-3737.2000.00999.x.

Davison, S.L., R.J. Bell, M. LaChina, S.L. Holden and S.R. Davis, 2009. The relationship between self-reported sexual satisfaction and general well-being in women. The Journal of Sexual Medicine, 6(10): 2690 - 2697.Available at: https://doi.org/10.1111/j.17436109.

Derogatis, L.R. and N. Melisaratos, 1979. The DSFI: A multidimensional measure of sexual functioning. Journal of Sex \& Marital Therapy, 5(3): 244-281.Available at: https://doi.org/10.1080/00926237908403732.

Diamond, L., 2003. What does sexual orientation orient? A biobehavioral model distinguishing romantic love and sexual desire. Psychological Review, 110(1): 173-192.Available at: https://doi.org/10.1037//0033-295x.110.1.173.

Do, N.K. and W. Bahr, 2017. The change in satisfaction level in the first two years of marriage. Proceeding of International Conference "The First Southeast Asia Regional Conference of Psychology: Human well-being and Sustainable Development. pp: $252-261$.

Dzara, K., 2010. Assessing the effect of marital sexuality on marital disruption. Social Science Research, 39(5): 715-724.Available at: https://doi.org/10.1016/j.ssresearch.2010.06.003.

Evans, H., 1995. Defining difference: The "scientific" construction of sexuality and gender in the people's Republic of China. Signs: Journal of Women in Culture and Society, 20(2): 357-394.Available at: https://doi.org/10.1086/494978.

Farley, F.H. and S.A. Davis, 1980. Personality and sexual satisfaction in marriage. Journal of Sex \& Marital Therapy, 6(1): 56-62.Available at: https://doi.org/10.1080/00926238008404246.

Fishbein, M. and I. Azjen, 1975. Belief, attitude, intention and behavior: An introduction to theory and research. Reading, MA: AddisonWesley.

Fiske, S.T. and S.E. Taylor, 2008. Social cognition: From brains to culture. New York: McGraw-Hill.

Henderson-King, D.H. and J. Veroff, 1994. Sexual satisfaction and marital well-being in the first years of marriage. Journal of Social and Personal Relationships, 11 (4): 509-534.Available at: https://doi.org/10.1177/0265407594114002.

Hurlbert, D.F., C. Apt and S.M. Rabehl, 1993. Key variables to understanding female sexual satisfaction: An examination of women in nondistressed marriages. Journal of Sex \& Marital Therapy, 19(2): 154-165.Available at: https://doi.org/10.1080/00926239308404899.

Khuat, T.H., B.D. Le and N.H. Nguyen, 2009. Sex is easy to joke, it's hard to say. Hanoi: Edition Tri Thuc.

Lawrance, K. and E.S. Byers, 1995. Sexual satisfaction in long-term heterosexual relationships: The interpersonal exchange model of sexual satisfaction. Personal Relationships, 2(4): 267-285.Available at: https://doi.org/10.1111/j.1475-6811.1995.tbooo92.x.

Lawrance, K. and E.S. Byers, 1998. Interpersonal exchange model of sexual satisfaction questionaire. In C.M.Davis, W.L.Yarber, R.Baureman, G.Schreer, and S.L.Davis, Eds., Sexuality related measure: A compendium. Thousand Oaks, CA: Sage.

Le, T.T.H., A.C. Tran and T.B. Lam, 2017. Sex and marriage happiness. Journal of Psychology, 11(224): 13-23.

Long, J.S., S.N. Smith, W.A. Fisher and M. Sand, 2011. Sexual satisfaction and relationship happiness in midlife and older couples in five countries sexual satisfaction and relationship happiness in midlife. Archives of Sexual Behavior, 40(4): 741 - 753.Available at: https://doi.org/10.1007/s 10508-010-9703-30.

Luu, T.L., 2017. Some factors affect satisfaction with married life (through some studies in the world). Journal of Human Reasearch, 10(97): 1 -14 .

MacNeil, S. and E.S. Byers, 2005. Dyadic assessment of sexual self-disclosure and sexual satisfaction in heterosexual dating couples. Journal of Social and Personal Relationships, 22(2): 169-181.Available at: https://doi.org/10.1177/0265407505050942.

Nguyen, H.D., 2015. Marriage satisfaction and factors that influence. Journal of Family and Gender Studies, 4(25): 3-14.

Nguyen, T.H., 2016. Satisfaction with women's family life with domestic violence. Journal of Psychology, 8(209): 34-44.

Pan, S., 1993. A sex revolution in current China. Journal of Psychology \& Human Sexuality, 6(2): 1-14.

Przybyla, D.P.J. and D. Byrne, 1981. Sexual relationships. In S.Duck and R.Gilmour, Eds., Personal relationships: Studying personal relationships. Orlando: Academic Press.

Purnine, D.M. and M.P. Carey, 1997. Interpersonal communication and sexual adjustment: The roles of understanding and agreement. Journal of Consulting and Clinical Psychology, 65(6): 1017-1025.Available at: https://doi.org/10.1037/0022-006x.65.6.1017. 
Rainer, H. and I. Smith, 2012. Education, communication and wellbeing: An application to sexual satisfaction. International Review for Social Science, 64(4): 581-598.Available at: https://doi.org/10.1111/kykl.12007.

Renaud, C., E.S. Byers and S. Pan, 1997. Sexual and relationship satisfaction in mainland China. Journal of Sex Research, 34(4): 399410.Available at: https://doi.org/10.1080/00224499709551907.

Rosen, R.C. and G.A. Bachmann, 2008. Sexual well-being, happiness, and satisfaction, in women: The case for a new conceptual paradigm Journal of Sex \& Marital Therapy, 34(4): 291-297.Available at: https://doi.org/10.1080/00926230802096283.

Schenk, J., H. Pfrang and A. Rausche, 1983. Personality traits versus the quality of the marital relationship as the determinant of marital sexuality. Archives of Sexual Behavior, 12(1): 31-42.Available at: https://doi.org/10.1007/bfo1542114.

Snyder, D.K., 1983. Clinical and research applications of the marital satisfaction inventory. In E.E.Filsinger, Eds., Marriage and family assessment: A sourcebook for family therapy. Beverly Hills, CA: Sage Publications.

Spanier, G.B., 1976. Measuring dyadic adjustment: New scales for assessing the quality of marriage and similar dyads. Journal of Marriage and the Family, 38(1): 15-28.Available at: https://doi.org/10.2307/350547.

Sprecher, S., 2002. Sexual satisfaction in premarital relationships: Associations with satisfaction, love, commitment, and stability. Journal of Sex Research, 39(3): 190-196.Available at: https://doi.org/10.1080/00224490209552141.

Wenner, C.A., 2010. Is sex important to marital satisfaction or is marital satisfaction important to sex? Top-down and bottom-up processing in the bedroom. A Thesis Presented for the Master of Arts Degree, University of Tennesse. Knoxvill.

Yeh, H.C., F.O. Lorenz, K.A.S. Wickrama, R.D. Conger and G.H. Elder, 2006. Relationships among sexual satisfaction, marital quality, and marital instability at midlfe. Journal of Family Psychology, 20(2): 339-343.Available at: https://doi.org/10.1037/08933200.20.2.339.

Citation | Trinh Thi Linh (2019). Sexual and Marital Satisfaction among Vietnamese People. International Journal of Social Sciences and English Literature, 3: 6-11.

\section{History:}

Received: 10 December 2018

Revised: 15 January 2019

Accepted: 20 February 2019

Published: 9 April 2019

Licensed: This work is licensed under a Creative Commons

Attribution 3.0 License $($ (c) $)$ Er

Publisher: Eastern Centre of Science and Education
Acknowledgement: The author would like to address her thank to PhanThi Hanh for her assistance with data collection and data preparation.

Funding: The author gratefully acknowledges a research grant from the Vietnam National University (VNU-Hanoi) (QG.16.47).

Competing Interests: The authors declare that they have no conflict of Competing Interests: The authors declare that they have no conflict of
interests.

Transparency: The author confirms that the manuscript is an honest, accurate, and transparent account of the study was reported; that no vital features of the study have been omitted; and that any discrepancies from the study as planned have been explained.

Ethical: This study follows all ethical practices during writing.

Eastern Centre of Science and Education is not responsible or answerable for any loss, damage or liability, etc. caused in relation to/arising out of the use of the content. Any queries should be directed to the corresponding author of the article. 